\title{
The distress and needs of Chinese patients with pituitary adenoma: a preliminary survey
}

Meifen Shen' ${ }^{1}$, Guixiao Sheng ${ }^{2}$, Yan Yang ${ }^{3}$, Chao $\mathrm{Wu}^{3}$, Chen $\mathrm{Ma}^{3}$, Li Yang ${ }^{3}$, Yulun Huang

${ }^{1}$ Department of Nursing, Dushu Lake Hospital Affiliated to Soochow University, Suzhou, Jiangsu Province, China

${ }^{2}$ Department of Nursing, the First Affiliated Hospital of Zhejiang University, Suzhou, Jiangsu Province, China

3Department of Neurosurgery, the First Affiliated Hospital of Soochow University, Suzhou, Jiangsu Province, China

Submitted: 29 June 2021; Accepted: 12 November 2021

Online publication: 21 November 2021

Arch Med Sci

DOI: https://doi.org/10.5114/aoms/143886

Copyright $\odot 2021$ Termedia \& Banach

\section{Abstract}

Introduction: It is necessary to investigate the current psychological distress and needs status of patients with pituitary adenoma in China.

Material and methods: Patients with pituitary adenoma treated in our hospital between May 2019 and December 2019 were included. The psychological distress and needs scale for pituitary adenoma patients was used to investigate the psychological distress and needs of patients. Additionally, univariate and multiple linear regression analyses were conducted to analyze the influencing factors.

Results: A total of 254 valid questionnaires were included. The total psychological distress and need score of patients with pituitary adenoma was $23.89 \pm 18.41$ and $21.91 \pm 20.03$ points respectively. There were significant differences in the psychological distress score according to different occupational status, personal income, types of pituitary adenomas, size of pituitary adenoma, invasiveness, endocrine level and history of surgery (all $p<0.05$ ). The size of pituitary adenoma, endocrine level and pituitary adenoma type were the influencing factors of patients' psychological distress (all $p<0.05$ ). There were significant differences in the need score according to different age, occupational status, personal income, types of pituitary adenomas and endocrine level (all $p<0.05$ ). Endocrine level, other rare types of pituitary adenoma and age were the influencing factors of patients' needs (all $p<0.05$ ). Conclusions: Our study is one of the few studies focused on the psychological distress and needs status of Chinese patients with pituitary adenoma. Medical staff should pay attention to the psychological distress of patients with the large, rare type of pituitary adenomas and abnormal endocrine level, and apply appropriate interventions to alleviate their psychological distress.

Key words: distress, needs, pituitary adenoma, China, nursing, care.

\section{Introduction}

Pituitary adenoma is a neuroendocrine tumor that originates from the anterior pituitary. It is the most common pituitary disease, accounting for about $10-15 \%$ of intracranial tumors [1]. Pituitary adenomas cause mass effect and endocrine disorders [2, 3]. The space-occupying effect causes neurological symptoms such as headache, dizziness, decreased vision,

\author{
Corresponding authors: \\ Li Yang, Meifen Shen \\ Department of Nursing \\ Dushu Lake Hospital \\ Affiliated to \\ Soochow University \\ Suzhou \\ Jiangsu Province, China \\ Phone: 138159032874 \\ Fax: 002907851022 \\ E-mail: bixieliaoqiaolu@163. \\ com
}


and visual field defects [4]. Growth hormone adenoma causes excessive growth of soft tissues and bones in the patient's body, and excessive growth hormone also affects multiple systems and organs in the patient's body [5]. Even after active surgery, and drug and radiotherapy treatment, not all patients' symptoms can be improved. Faced with problems such as unimprovable symptoms, long-term effects of hormone overdose, the possibility of tumor recurrence, long-term medication and hormone monitoring, patients can also suffer from certain psychological distress, which affects their quality of life [6]. In addition, in the course of long-term illness, patients still have a series of needs, which affect their effective response to the disease [7]. An in-depth understanding of the psychological distress and needs of patients with pituitary adenoma is of great significance for improving the quality of life of patients.

Many studies $[8,9]$ have shown that patients with pituitary adenoma have certain psychological distress and it seriously affects their quality of life. Studies $[10,11]$ have shown that compared with healthy controls, patients with pituitary diseases have a higher prevalence of severe depression and adjustment disorders, and patients with pituitary diseases have a higher incidence of psychosomatic syndromes such as irritability, low morale, and continuous somatization. Moreover, patients with pituitary adenoma have different needs. A qualitative study [12] reported that patients hope to obtain more information about diseases from medical staff, such as adverse drug reactions, the effects of diseases on physical, mental, cognitive, sexual function and fertility. Patients expect medical staff to give more advice on stress management and lifestyle [13]. Understanding the current psychological distress and needs of patients with pituitary adenoma can provide a scientific basis for formulating targeted intervention measures. However, there are few studies on the psychological distress and needs of patients with pituitary adenomas, which needs further investigations. Therefore, this study aimed to understand the psychological distress and needs of patients with pituitary adenoma in China, and analyze the influencing factors of psychological distress and needs of patients with pituitary adenoma, to provide a theoretical basis for the management of pituitary adenoma.

\section{Material and methods}

\section{Ethical consideration}

In this study, all methods were conducted in accordance with the relevant guidelines and regulations. This study passed the ethical review of our hospital (review number: ECSU-20019000115), and all included patients agreed to participate in this study, and written informed consents had been obtained from all the included patients.

\section{Sample size calculation}

It has been reported [14] that factor analysis should be conducted for generally less than 40 items. In most cases, a sample size of 200 is sufficient. It was considered [15] that for factor analysis, the number of pre-samples should be 5 times the number of entries; if the ratio of the number of pre-samples to the number of entries was $10: 1$, the result would be more stable. The number of items in our survey scale is 33. Except for one open question, it was estimated that there were 32 items for factor analysis. According to the principle of sample size calculation, the sample size should be 160 to 320 .

\section{Patients}

We adopted the convenience sampling method and selected patients with pituitary adenoma who had been treated in the Department of Neurosurgery of our hospital from May 2019 to December 2019 as the research populations. The inclusion criteria for patients in this study were as follows: 1) age $\geq 18$ years old; 2 ) patients were diagnosed with pituitary adenoma; 3) patients voluntarily participated in this study; 4) patients received pituitary adenoma surgery or related medical treatment for 3 months or more.

The exclusion criteria of patients in this study were as follows: 1) those patients who could not communicate normally and finished the survey; 2) patients with previous mental illnesses such as schizophrenia and depression or dementia; 3) patients who did not agree to participant in this study.

\section{Survey tools \\ General information}

The demographic information included age, gender, education level, and medical insurance type. The disease-related information included pituitary adenoma classification, pituitary adenoma size, invasiveness, surgical status and medication. Tumor invasiveness was defined according to the Knosp invasiveness grade of pituitary adenoma: Knosp grade $\geq 3$ indicated that the tumor was aggressive; Knosp grade $\leq 2$ indicated that the tumor was not invasive.

\section{Psychological distress and needs scale}

The psychological distress and needs in patients with pituitary adenoma were investigated by the Chinese version of the psychological distress and 
needs scale for patients with pituitary adenoma [16]. The item level content validity index (I-CVI) of each item in the Chinese version of the scale was $0.833-1$, and the average scale level content validity index (S-CVI) was 0.958. The Cronbach's $\alpha$ coefficient in the "mental distress" part was 0.945 , and the test-retest reliability was 0.917 ; the Cronbach's $\alpha$ in the "needs" part was 0.950, and the test-retest reliability was 0.913 . The scale contained a total of 28 items. The first 27 items evaluated five dimensions: emotional problems, social function, physical and cognitive problems, negative disease perception, and sexual function. The scale adopted a percentile scoring method. The scores of each dimension and the total scale were 0-100 points. The calculation formula was: dimension (total scale) score $=$ actual score of the dimension (total scale)/highest possible score $\times 100$. The higher the psychological distress score was, the more serious was the psychological distress, the higher was the demand score, and the more the patient expected support from medical staff.

\section{Data collection and quality control}

We selected appropriate pituitary adenoma patients based on the inclusion and exclusion criteria established by the study, and the investigator himself explained the purpose and significance of the study to the patient, and issued informed consent and questionnaires. In the case of informed consent, a unified guideline was used to introduce the method and requirements for filling out the questionnaire in this study, which was filled out by the patient himself. If patients had any questions during the questionnaire filling process, we used unified explanatory language to answer patients. After completing the questionnaire, the researchers conducted on-site quality control, including checked the questionnaire item by item to check the incomplete or unclear information with obvious logical errors.

\section{Ethics approval and consent to participate}

In this study, all methods were performed in accordance with the relevant guidelines and regulations. This study passed the ethical review of our hospital (review number: ECSU-20019000115), and all included patients had agreed to participate in this study, and written informed consents had been obtained from all the included patients.

\section{Statistical analysis}

We used SPSS25.0 for statistical analysis of the data. The measurement data were expressed as mean \pm standard deviation, and the counting data were expressed as frequency and percentage. The $t$-test and analysis of variance were used for sin- gle factor analysis with the Bonferroni method, and multiple linear regression was used to analyze the influence of various factors on the psychological distress and needs of patients with pituitary adenoma. In this study, the difference was statistically significant when $p<0.05$.

\section{Results}

\section{Characteristics of included patients}

A total of 270 questionnaires were distributed, and 254 valid questionnaires were returned. The effective response rate was $94.07 \%$. As presented in Table I, the patients were $20-72$ years old, with an average age of $41.32 \pm 12.45$ years. Among them, 15 (5.90\%) patients received gamma knife treatment, 178 (70.1\%) patients received surgery, $12(6.74 \%)$ patients only received craniotomy, 161 (90.45\%) people only received transnasal sphenoid approach surgery, 5 (2.81\%) patients received both craniotomy and transnasal sphenoid approach surgery, and 28 (11.02\%) patients took anti-depressant treatment after surgery. The characteristics of included patients are presented in Table I.

\section{Psychological distress and needs in patients with pituitary adenoma}

The total psychological distress score of patients with pituitary adenoma was $23.89 \pm 18.41$ points, of which the negative disease perception dimension score was the highest, and the social function dimension score was the lowest. The total need score of patients with pituitary adenoma was $21.91 \pm 20.03$ points, of which the negative disease perception dimension scored the highest, and the social function dimension scored the lowest number of points (Table II).

As presented in Table III, univariate analysis indicated that there were significant differences of psychological distress score according to different occupational status, personal income, types of pituitary adenomas, size of pituitary adenoma, invasiveness, endocrine level and history of surgery (all $p<0.05$ ).

As presented in Table IV, multiple linear regression analysis showed that the size of pituitary adenoma, endocrine level and pituitary adenoma type were the influencing factors of patients' psychological distress (all $p<0.05$ ).

As presented in Table $\mathrm{V}$, univariate analysis indicated that there were significant differences of need score according to different age, occupational status, personal income, types of pituitary adenomas and endocrine level (all $p<0.05$ ).

As presented in Table VI, multiple linear regression analysis showed that endocrine level, other rare types of pituitary adenoma and age were the influencing factors of patients' needs (all $p<0.05$ ). 
Table I. Characteristics of included patients $(n=254)$

\begin{tabular}{|c|c|}
\hline Items & Cases (\%) \\
\hline \multicolumn{2}{|l|}{ Age: } \\
\hline$\leq 44$ & $164(64.2)$ \\
\hline $45-59$ & $62(24.4)$ \\
\hline$\geq 60$ & $28(11.0)$ \\
\hline \multicolumn{2}{|l|}{ Gender: } \\
\hline Female & $173(68.1)$ \\
\hline Male & $81(31.9)$ \\
\hline \multicolumn{2}{|l|}{ Marital status: } \\
\hline Married & $217(85.4)$ \\
\hline Unmarried & $34(13.4)$ \\
\hline Divorced & $3(1.2)$ \\
\hline \multicolumn{2}{|l|}{ Child bearing: } \\
\hline Yes & $205(80.7)$ \\
\hline No & $49(19.3)$ \\
\hline \multicolumn{2}{|l|}{ Occupational status: } \\
\hline Employed & $209(82.3)$ \\
\hline Unemployed/retired & $45(17.7)$ \\
\hline \multicolumn{2}{|l|}{ Education level: } \\
\hline Primary school & $26(10.2)$ \\
\hline Junior high school & $53(20.9)$ \\
\hline $\begin{array}{l}\text { High school or occupational } \\
\text { technique school }\end{array}$ & $50(19.7)$ \\
\hline University & $125(49.2)$ \\
\hline \multicolumn{2}{|l|}{ Personal income (RMB): } \\
\hline None & $26(10.2)$ \\
\hline$<3000$ & $56(22.0)$ \\
\hline $3000-6000$ & $93(36.6)$ \\
\hline$>6000$ & $79(31.1)$ \\
\hline
\end{tabular}

\begin{tabular}{|c|c|}
\hline Items & Cases (\%) \\
\hline \multicolumn{2}{|l|}{ Medical insurance: } \\
\hline Self-covered & $25(9.8)$ \\
\hline $\begin{array}{l}\text { New rural cooperative medical } \\
\text { insurance }\end{array}$ & $33(13.0)$ \\
\hline $\begin{array}{l}\text { Medical insurance for urban } \\
\text { residents }\end{array}$ & $196(77.2)$ \\
\hline \multicolumn{2}{|l|}{ Types of pituitary adenomas: } \\
\hline Growth hormone type & $55(21.7)$ \\
\hline Corticotropin type & $20(7.9)$ \\
\hline Non-function type & $76(29.9)$ \\
\hline Prolactin type & $93(36.6)$ \\
\hline Other rare types & $10(3.9)$ \\
\hline \multicolumn{2}{|l|}{ Size of pituitary adenoma: } \\
\hline Microadenoma & $88(34.6)$ \\
\hline Large adenoma & $155(61.0)$ \\
\hline Giant adenoma & $11(4.3)$ \\
\hline \multicolumn{2}{|l|}{ Invasiveness: } \\
\hline Yes & $65(25.6)$ \\
\hline No & $189(74.4)$ \\
\hline \multicolumn{2}{|l|}{ Endocrine level: } \\
\hline Normal & $111(43.7)$ \\
\hline Abnormal & $143(56.3)$ \\
\hline \multicolumn{2}{|l|}{ History of surgery: } \\
\hline Yes & $178(70.1)$ \\
\hline No & $76(29.9)$ \\
\hline \multicolumn{2}{|l|}{ Anti-depressants use after surgery: } \\
\hline Yes & $28(11.02)$ \\
\hline No & $226(88.98)$ \\
\hline
\end{tabular}

Table II. Psychological distress and need scores of patients with pituitary adenoma

\begin{tabular}{|lcl|}
\hline Dimensions & Psychological distress score & Needs scores \\
\hline Emotional problems & $26.92 \pm 23.28$ & $25.49 \pm 26.62$ \\
\hline Social function & $11.71 \pm 18.05$ & $10.65 \pm 18.27$ \\
\hline Physical and cognitive problems & $27.39 \pm 21.54$ & $27.61 \pm 24.54$ \\
\hline Negative disease perception & $34.82 \pm 23.95$ & $35.41 \pm 27.42$ \\
\hline Sexual function & $14.22 \pm 23.73$ & $15.16 \pm 27.38$ \\
\hline Total scale score & $23.89 \pm 18.41$ & $21.91 \pm 20.03$ \\
\hline
\end{tabular}

\section{Discussion}

A total of 254 patients with pituitary adenoma were investigated in this study. Among them, prolactin type patients were the most numerous, followed by non-functioning patients, acromegaly patients, Cushing's disease patients, and other rare type patients. Our findings are similar to previous related epidemiological survey results $[17,18]$, in which the prevalence of prolactinoma is the highest, followed by non-functioning type, acromegaly and Cushing's disease. Although the prevalence of acromegaly and Cushing's disease is relatively low, China's population base is large and the number of patients is also large [19]. The psychological distress and needs scale of patients with pituitary adenoma is a self-rating scale, which requires higher reading comprehension of patients [20]. Also, 
Table III. Univariate analysis of psychological distress scores in patients with pituitary adenoma

\begin{tabular}{|c|c|c|c|}
\hline Variables & Psychological distress scores & $F / t$ & $P$-value \\
\hline \multicolumn{4}{|l|}{ Age: } \\
\hline$<60$ & $24.81 \pm 20.24$ & 0.389 & 0.698 \\
\hline$\geq 60$ & $23.84 \pm 15.24$ & & \\
\hline \multicolumn{4}{|l|}{ Gender: } \\
\hline Female & $22.53 \pm 17.69$ & -1.727 & 0.085 \\
\hline Male & $26.79 \pm 19.64$ & & \\
\hline \multicolumn{4}{|l|}{ Marital status; } \\
\hline Married & $24.24 \pm 18.69$ & 0.295 & 0.745 \\
\hline Unmarried & $22.11 \pm 16.91$ & & \\
\hline Divorced & $19.14 \pm 18.06$ & & \\
\hline \multicolumn{4}{|l|}{ Child bearing: } \\
\hline Yes & $24.07 \pm 18.95$ & 0.322 & 0.748 \\
\hline No & $23.12 \pm 16.10$ & & \\
\hline \multicolumn{4}{|l|}{ Occupational status: } \\
\hline Employed & $22.68 \pm 16.40$ & -2.274 & 0.024 \\
\hline Unemployed/retired & $29.51 \pm 25.25$ & & \\
\hline \multicolumn{4}{|l|}{ Education level: } \\
\hline Primary school & $30.06 \pm 15.99$ & 1.529 & 0.208 \\
\hline Junior high school & $20.74 \pm 15.80$ & & \\
\hline High school or occupational technique school & $23.30 \pm 19.62$ & & \\
\hline University & $24.19 \pm 19.25$ & & \\
\hline \multicolumn{4}{|l|}{ Personal income (RMB): } \\
\hline None & $36.18 \pm 28.49$ & 4.892 & 0.003 \\
\hline$<3000$ & $20.35 \pm 15.05$ & & \\
\hline $3000-6000$ & $23.63 \pm 15.83$ & & \\
\hline$>6000$ & $22.67 \pm 17.96$ & & \\
\hline \multicolumn{4}{|l|}{ Medical insurance: } \\
\hline Self-covered & $26.74 \pm 18.90$ & 0.404 & 0.668 \\
\hline New rural cooperative medical insurance & $24.72 \pm 19.51$ & & \\
\hline Medical insurance for urban residents & $23.39 \pm 18.22$ & & \\
\hline \multicolumn{4}{|l|}{ Types of pituitary adenomas: } \\
\hline Growth hormone type & $27.72 \pm 19.37$ & 3.973 & 0.004 \\
\hline Corticotropin type & $29.26 \pm 21.09$ & & \\
\hline Non-function type & $22.36 \pm 16.63$ & & \\
\hline Prolactin type & $20.11 \pm 17.77$ & & \\
\hline Other rare types & $38.89 \pm 15.15$ & & \\
\hline \multicolumn{4}{|l|}{ Size of pituitary adenoma: } \\
\hline Microadenoma & $20.74 \pm 19.56$ & 3.690 & 0.026 \\
\hline Large adenoma & $24.87 \pm 17.30$ & & \\
\hline Giant adenoma & $35.27 \pm 19.69$ & & \\
\hline \multicolumn{4}{|l|}{ Invasiveness: } \\
\hline Yes & $28.39 \pm 19.40$ & 2.303 & 0.022 \\
\hline No & $22.34 \pm 17.85$ & & \\
\hline \multicolumn{4}{|l|}{ Endocrine level: } \\
\hline Normal & $18.15 \pm 14.45$ & -4.727 & $<0.001$ \\
\hline Abnormal & $28.35 \pm 19.90$ & & \\
\hline \multicolumn{4}{|l|}{ History of surgery: } \\
\hline Yes & $26.00 \pm 19.16$ & 2.830 & 0.005 \\
\hline No & $18.96 \pm 15.54$ & & \\
\hline
\end{tabular}


Table IV. Multiple linear regression analysis of influencing factors of psychological distress in patients with pituitary adenoma

\begin{tabular}{|c|c|c|c|c|}
\hline Variables & $\beta$ & SE & $t$ & $P$-value \\
\hline Constant & 7.574 & 5.886 & 1.287 & 0.199 \\
\hline Size of pituitary adenoma & 5.800 & 2.532 & 2.291 & 0.023 \\
\hline Endocrine level & 10.162 & 2.460 & 4.130 & 0.000 \\
\hline Corticotropin type of pituitary adenomas & 5.653 & 4.701 & 1.203 & 0.230 \\
\hline Non-function type of pituitary adenoma & 0.202 & 3.420 & 0.059 & 0.953 \\
\hline Prolactin type of pituitary adenoma & -0.801 & 3.453 & -0.232 & 0.817 \\
\hline Other rare types of pituitary adenoma & 13.761 & 5.977 & 2.302 & 0.022 \\
\hline
\end{tabular}

patients with a higher education level pay more attention to their own psychosocial problems, and they will have better acceptance of the survey and a higher degree of cooperation [21, 22].

The results of this study showed that unemployed patients have higher psychological distress and need scores than working patients, and non-income patients have higher psychological distress and demand levels. A previous study [23] found that occupation is one of the influencing factors of the quality of life of patients with pituitary adenoma. It has been reported $[24,25]$ that $28 \%$ of patients with pituitary adenoma have no paid work, and Cushing's disease has the highest proportion of unpaid work, reaching $47 \%$. Working patients can be distracted to a certain extent through work [26]. Not only can they get financial support from the job, but they can also get more information and social support to promote the patient's physical and mental health $[27,28]$. Therefore, medical staff should pay more attention to the psychological state and needs of patients with pituitary adenoma who are not working and have no stable income, and help patients choose cost-effective treatment options to reduce the psychological burden of medical expenses on patients [29].

We found that patients with other rare types of pituitary adenomas have the highest levels of psychological distress and needs. The possible reason may be that the mixed adenomas can secrete multiple hormones, leading to a variety of endocrine disorders [30]. The clinical manifestations are diverse, overlapping, and more complex, which causes a greater psychological burden on patients and more needs. Patients with thyroid stimulating hormone adenoma and gonadotropin adenoma often seek medical treatment in multiple departments, and the medical treatment process is often complicated and tortuous [31]. Therefore, medical staff should pay special attention to the psychological conditions of patients with rare type pituitary adenomas, explain the clinical manifestations, treatment plans, and post-treatment of the disease, help patients build confidence in treating the disease, and alleviate the psychological distress of patients. Additionally, it is necessary to understand the needs of patients and develop a personalized care plan.

Endocrine level is an important factor affecting patients' psychological distress and needs. Studies [31, 32] have shown that after active treatments such as surgery and radiotherapy, residual functional pituitary adenomas will secrete excessive hormones. At present, relevant research focuses on the health management of patients with pituitary adenomas during the perioperative period, while neglecting the long-term follow-up health management of patients with pituitary adenomas that have developed into chronic diseases [33]. Therefore, patients with pituitary adenomas in long-term follow-up urgently need effective health management to improve their self-management ability, reduce their psychological burden and improve their quality of life.

The larger the pituitary adenoma, the more aggressive it is, and the higher the level of psychological distress in patients with a history of surgery. A previous study [34] showed that the size of preoperative pituitary adenomas is a factor that affects the total resection rate of endoscopic sinus surgery. The larger the preoperative pituitary adenoma size, the lower is the total resection rate [35]. In large adenomas and giant adenomas, the total cut rate under the microscope is $14.3-56.4 \%$ [36]. Patients with incomplete pituitary adenomas have a low endocrine remission rate [37]. Furthermore, patients undergoing surgery will undergo longer-term recovery, and complications such as hypopituitarism and diabetes insipidus may occur after surgery [38-40]. Therefore, medical staff should pay attention to the psychological distress and needs of patients with giant adenomas, surgical history, and invasive pituitary adenomas.

This present study revealed that patients under the age of 60 have a higher level of needs than those over the age of 60 . The possible reason may be that young patients with pituitary adenomas need to return to work, and their social and family responsibilities are heavier [41, 42]. Also, 
Table V. Univariate analysis of needs in patients with pituitary adenoma

\begin{tabular}{|c|c|c|c|}
\hline Variables & Need scores & $F / t$ & $P$-value \\
\hline \multicolumn{4}{|l|}{ Age: } \\
\hline$<60$ & $22.63 \pm 20.54$ & 2.161 & 0.036 \\
\hline$\geq 60$ & $16.10 \pm 14.24$ & & \\
\hline \multicolumn{4}{|l|}{ Gender: } \\
\hline Female & $20.46 \pm 19.29$ & -1.700 & 0.090 \\
\hline Male & $25.02 \pm 21.33$ & & \\
\hline \multicolumn{4}{|l|}{ Marital status: } \\
\hline Married & $22.02 \pm 20.24$ & 0.085 & 0.918 \\
\hline Unmarried & $21.65 \pm 19.23$ & & \\
\hline Divorced & $17.28 \pm 19.21$ & & \\
\hline \multicolumn{4}{|l|}{ Child bearing: } \\
\hline Yes & $21.95 \pm 20.58$ & 0.056 & 0.956 \\
\hline No & $21.77 \pm 17.75$ & & \\
\hline \multicolumn{4}{|l|}{ Occupational status: } \\
\hline Employed & $20.68 \pm 18.25$ & -2.119 & 0.035 \\
\hline Unemployed/retired & $27.61 \pm 26.33$ & & \\
\hline \multicolumn{4}{|l|}{ Education level: } \\
\hline Primary school & $27.74 \pm 16.39$ & 1.815 & 0.145 \\
\hline Junior high school & $17.26 \pm 17.62$ & & \\
\hline High school or occupational technique school & $21.37 \pm 20.72$ & & \\
\hline University & $22.89 \pm 21.15$ & & \\
\hline \multicolumn{4}{|l|}{ Personal income (RMB): } \\
\hline None & $34.87 \pm 28.56$ & 5.274 & 0.002 \\
\hline$<3000$ & $16.53 \pm 16.19$ & & \\
\hline $3000-6000$ & $22.22 \pm 18.53$ & & \\
\hline$>6000$ & $21.10 \pm 19.30$ & & \\
\hline \multicolumn{4}{|l|}{ Medical insurance: } \\
\hline Self-covered & $25.85 \pm 20.39$ & 0.540 & 0.583 \\
\hline New rural cooperative medical insurance & $21.54 \pm 20.06$ & & \\
\hline Medical insurance for urban residents & $21.13 \pm 19.85$ & & \\
\hline \multicolumn{4}{|l|}{ Types of pituitary adenomas: } \\
\hline Growth hormone type & $24.75 \pm 21.20$ & 2.644 & 0.034 \\
\hline Corticotropin type & $26.16 \pm 23.12$ & & \\
\hline Non-function type & $19.37 \pm 17.79$ & & \\
\hline Prolactin type & $19.73 \pm 20.11$ & & \\
\hline Other rare types & $37.41 \pm 15.00$ & & \\
\hline \multicolumn{4}{|l|}{ Size of pituitary adenoma: } \\
\hline Microadenoma & $19.54 \pm 21.00$ & 2.242 & 0.108 \\
\hline Large adenoma & $22.51 \pm 19.09$ & & \\
\hline Giant adenoma & $32.49 \pm 22.91$ & & \\
\hline \multicolumn{4}{|l|}{ Invasiveness: } \\
\hline Yes & $25.68 \pm 21.27$ & 1.767 & 0.078 \\
\hline No & $20.62 \pm 19.48$ & & \\
\hline \multicolumn{4}{|l|}{ Endocrine level: } \\
\hline Normal & $16.07 \pm 16.49$ & -4.226 & $<0.001$ \\
\hline Abnormal & $26.44 \pm 21.38$ & & \\
\hline \multicolumn{4}{|l|}{ History of surgery: } \\
\hline Yes & $23.38 \pm 20.87$ & 1.798 & 0.073 \\
\hline No & $18.47 \pm 17.58$ & & \\
\hline
\end{tabular}


Table VI. Multiple linear regression analysis of influencing factors of needs in patients with pituitary adenomas

\begin{tabular}{|lcccc|}
\hline Variables & $\beta$ & SE & $\boldsymbol{t}$ & $\boldsymbol{P}$-value \\
\hline Constant & 24.872 & 4.797 & 5.185 & 0.000 \\
\hline Endocrine level & 9.489 & 2.726 & 3.481 & 0.001 \\
\hline Corticotropin type of pituitary adenomas & 2.242 & 5.018 & 0.447 & 0.655 \\
\hline Non-function type of pituitary adenoma & 1.569 & 3.849 & 0.408 & 0.684 \\
\hline Prolactin type of pituitary adenoma & -1.656 & 3.385 & -0.489 & 0.625 \\
\hline Other rare types of pituitary adenoma & 15.642 & 6.618 & 2.364 & 0.019 \\
\hline Personal income (RMB) & -1.119 & 1.531 & -0.731 & 0.465 \\
\hline Age & -9.394 & 4.295 & -2.187 & 0.030 \\
\hline Occupation & -7.063 & 3.946 & -1.790 & 0.075 \\
\hline
\end{tabular}

pituitary adenomas may cause changes in the patient's appearance, affecting marriage, childbirth, and sexual life [43]. Young patients pay more attention to the long-term adverse effects of the disease and have higher expectations for recovery [44]. Therefore, it is necessary to strengthen the long-term follow-up of young patients, teach patients to manage their own health and provide certain psychological support to meet the needs of patients.

There are several shortcomings in this study that must be considered. Firstly, the influencing factors included in this study explain only $13.7 \%$ and $12.4 \%$ of the psychological distress and needs variation of patients with pituitary adenoma. Other factors such as drug treatment, duration of illness, and disease acceptance were not considered. It is recommended that future studies expand the scope of influencing factors and explore other factors that may be involved in the psychological distress and needs of patients with pituitary adenomas. Secondly, the research subjects included in this study were patients who had undergone surgery or medication for 3 months or more, and the results of the study are applicable to patients who have been followed up out of hospital for a long time. It is suggested that follow-up studies can also include hospitalized patients and patients in the recovery stage within 3 months after surgery to explore the psychological distress and needs of patients with pituitary adenomas at different stages of the disease. Thirdly, due to the limitations of manpower and material resources and the low incidence of some types of pituitary adenomas, there are only 20 patients with Cushing's disease in the investigation, which cannot well represent the psychological distress and level of needs of patients with Cushing's disease. Our study is one of the few studies focused on the psychological distress and needs status of Chinese patients with pituitary adenoma. We will continue to include patients with Cushing's disease, expand the sample size, and analyze the psycholog- ical distress and needs of patients with Cushing's disease more comprehensively in the future.

In conclusion, patients with pituitary adenomas have certain psychological distress and needs, especially in the dimensions of perception of negative diseases, physical and cognitive problems. Patients who are unemployed or retired, with lower income, rarely typed pituitary adenomas and abnormal endocrine levels have higher levels of psychological distress and needs. Clinically, attention should be paid to the above-mentioned patients' psychological distress and needs, and targeted support and psychological interventions should be given to improve patients' self-management ability and quality of life.

\section{Conflict of interest}

The authors declare no conflict of interest.

\section{References}

1. Oh JS, Kim HJ, Hann HJ, et al. Incidence, mortality, and cardiovascular diseases in pituitary adenoma in Korea: a nationwide population-based study. Pituitary 2021; 24: 38-47.

2. Cote DJ, Smith TR, Kaiser UB, Laws ER, Stampfer MJ. Body habitus across the lifespan and risk of pituitary adenoma. J Clin Endocrinol Metab 2021; 106: e1591-602.

3. Ertek S. Molecular economy of nature with two thyrotropins from different parts of the pituitary: pars tuberalis thyroid-stimulating hormone and pars distalis thyroid-stimulating hormone. Arch Med Sci 2021; 17: 189-95.

4. Parkin K, Kapoor R, Bhat R, Greenough A. Genetic causes of hypopituitarism. Arch Med Sci 2020; 16: 27-33.

5. Castellanos LE, Misra M, Smith TR, Laws ER, lorgulescu JB. The epidemiology and management patterns of pediatric pituitary tumors in the United States. Pituitary 2021; 24: 412-9.

6. Liu Z, Zhang H, Liu S, Chen H. The functional evaluation of pituitary in patients with a surgical resection of sellar tumours. Arch Med Sci 2020; 16: 460-5.

7. Whipple SG, Savardekar AR, Rao S, Mahadevan A, Guthikonda B, Kosty JA. Primary tumors of the posterior pituitary gland: a systematic review of the literature in light of the new 2017 World Health Organization Clas- 
sification of Pituitary Tumors. World Neurosurg 2021; 145: 148-58.

8. Kao KT, Stargatt R, Zacharin M. Adult quality of life and psychosocial outcomes of childhood onset hypopituitarism. Horm Res Paediatr 2015; 84: 94-101.

9. Huguet I, Ntali G, Grossman A, Karavitaki N. Cushing's disease - quality of life, recurrence and long-term morbidity. Eur Endocrinol 2015; 11: 34-8.

10. Feelders RA, Pulgar SJ, Kempel A, Pereira AM. The burden of Cushing's disease: clinical and health-related quality of life aspects. Eur J Endocrinol 2012; 167: 311-26.

11. Postma MR, Netea-Maier RT, van den Berg G, et al. Quality of life is impaired in association with the need for prolonged postoperative therapy by somatostatin analogs in patients with acromegaly. Eur J Endocrinol 2012; 166: 585-92.

12. Chao W, Meifen S, Qi Y. Structural equation model of coping style, hope level and quality of life of patients after pituitary tumor surgery. Nursing Res 2016; 30: 4402-6.

13. Webb SM, Santos A, Aulinas A, et al. Patient-centered outcomes with pituitary and parasellar disease. Neuroendocrinology 2020; 110: 882-8.

14. Yang CJ, Huang GS, Xiao FR, Lou MF. Symptom distress and quality of life after stereotactic radiosurgery in patients with pituitary tumors: a questionnaire survey. PLoS One 2014; 9: e88460.

15. Jang MK, Park CG, Jang S, Kim EH. Prevalence and impact of postoperative headaches in nonfunctioning pituitary macroadenoma patients: a longitudinal cohort study. World Neurosurg 2020; 133: e633-9.

16. Yongxia S. Compilation and application of the nursing professional social support demand scale for cancer patients. Anhui Medical University 2015.

17. Tiemensma J, Biermasz NR, van der Mast RC, et al. Increased psychopathology and maladaptive personality traits, but normal cognitive functioning, in patients after long-term cure of acromegaly. J Clin Endocrinol Metab 2010; 95: E392-402.

18. Tiemensma J, Biermasz NR, Middelkoop HA, van der Mast RC, Romijn JA, Pereira AM. Increased prevalence of psychopathology and maladaptive personality traits after long-term cure of Cushing's disease. J Clin Endocrinol Metab 2010; 95: E129-41.

19. Guo X, Wang K, Yu S, et al. Patient characteristics, diagnostic delays, treatment patterns, treatment outcomes, comorbidities, and treatment costs of acromegaly in China: a nationwide study. Front Endocrinol 2020; 11: 610519.

20. Sievers $\mathrm{C}$, Ising $\mathrm{M}$, Pfister $\mathrm{H}$, et al. Personality in patients with pituitary adenomas is characterized by increased anxiety-related traits: comparison of 70 acromegalic patients with patients with non-functioning pituitary adenomas and age- and gender-matched controls. Eur J Endocrinol 2009; 160: 367-73.

21. Tiemensma J, Andela CD, Kaptein AA, et al. Psychological morbidity and impaired quality of life in patients with stable treatment for primary adrenal insufficiency: cross-sectional study and review of the literature. Eur J Endocrinol 2014; 171: 171-82.

22. Placzek H, Xu Y, Mu Y, Begelman SM, Fisher M. Clinical and economic burden of commercially insured patients with acromegaly in the united states: a retrospective analysis. J Manag Care Spec Pharm 2015; 21: 1106-12.

23. Solomon E, Branisteanu D, Dumbrava A, et al. Executive functioning and quality of life in acromegaly. Psychol Res Behav Manag 2019; 12: 39-44.
24. Andela CD, Tiemensma J, Kaptein AA, et al. The partner's perspective of the impact of pituitary disease: looking beyond the patient. J Health Psychol 2019; 24: 1687-97.

25. Alibas H, Uluc K, Kahraman Koytak P, et al. Evaluation of depressive mood and cognitive functions in patients with acromegaly under somatostatin analogue therapy. J Endocrinol Invest 2017; 40: 1365-72.

26. Lesen E, Granfeldt D, Houchard A, et al. Comorbidities, treatment patterns and cost-of-illness of acromegaly in Sweden: a register-linkage population-based study. Eur J Endocrinol 2017; 176: 203-12.

27. Christofides EA. Clinical importance of achieving biochemical control with medical therapy in adult patients with acromegaly. Patient Prefer Adherence 2016; 10: 1217-25.

28. Jakobsson Ung E, Olofsson AC, Bjorkman I, et al. The pre- and postoperative illness trajectory in patients with pituitary tumours. Endocr Connect 2019; 8: 878-86.

29. Yoshida K, Fukuoka H, Matsumoto R, et al. The quality of life in acromegalic patients with biochemical remission by surgery alone is superior to that in those with pharmaceutical therapy without radiotherapy, using the newly developed Japanese version of the AcroQoL. Pituitary 2015; 18: 876-83.

30. Crespo I, Santos A, Valassi E, Pires P, Webb SM, Resmini E. Impaired decision making and delayed memory are related with anxiety and depressive symptoms in acromegaly. Endocrine 2015; 50: 756-63.

31. Simpson GK, Koh ES, Whiting D, et al. Frequency, clinical correlates, and ratings of behavioral changes in primary brain tumor patients: a preliminary investigation. Front Oncol 2015; 5: 78.

32. Andela CD, Scharloo M, Pereira AM, Kaptein AA, Biermasz NR. Quality of life (QoL) impairments in patients with a pituitary adenoma: a systematic review of QoL studies. Pituitary 2015; 18: 752-76.

33. Yedinak CG, Fleseriu M. Self-perception of cognitive function among patients with active acromegaly, controlled acromegaly, and non-functional pituitary adenoma: a pilot study. Endocrine 2014; 46: 585-93.

34. Martin-Rodriguez JF, Madrazo-Atutxa A, Venegas-Moreno $E$, et al. Neurocognitive function in acromegaly after surgical resection of $\mathrm{GH}$-secreting adenoma versus naive acromegaly. PLoS One 2013; 8: e60041.

35. Sobrinho LG, Duarte JS, Paiva I, Gomes L, Vicente V, Aguiar P. Paternal deprivation prior to adolescence and vulnerability to pituitary adenomas. Pituitary 2012; 15 : 251-7.

36. Machado-Alba JE, Machado-Duque ME. Prescription patterns of long-acting somatostatin analogues. SAGE Open Med 2017; 5: 2050312117694795.

37. Geraedts VJ, Andela CD, Stalla GK, et al. Predictors of quality of life in acromegaly: no consensus on biochemical parameters. Front Endocrinol 2017; 8: 40.

38. Kyriakakis N, Lynch J, Gilbey SG, Webb SM, Murray RD. Impaired quality of life in patients with treated acromegaly despite long-term biochemically stable disease: results from a 5-years prospective study. Clin Endocrinol 2017; 86: 806-15.

39. Jawiarczyk-Przybylowska A, Szczesniak D, Ciulkowicz M, Bolanowski M, Rymaszewska J. Importance of illness acceptance among other factors affecting quality of life in acromegaly. Front Endocrinol 2019; 10: 899.

40. Gatto F, Campana C, Cocchiara F, et al. Current perspectives on the impact of clinical disease and biochemical control on comorbidities and quality of life in acromegaly. Rev Endocr Metab Disord 2019; 20: 365-81. 
41. Guo X, Wang K, Yu S, et al. Quality of life and its determinants in patients with treated acromegaly: a cross-sectional nationwide study in China. J Clin Endocrinol Metab 2021; 106: 211-25.

42. Kamusheva M, Vandeva S, Mitov K, et al. New epidemiological, clinical and economic data for patients with acromegaly in Bulgaria. Front Public Health 2020; 8: 147.

43. Oliveira BA, Araujo B, Dos Santos TM, et al. Healthrelated quality of life in acromegaly patients: results from generic and disease-specific questionnaires. Indian J Endocrinol Metab 2020; 24: 402-5.

44. Broersen LHA, Zamanipoor Najafabadi AH, Pereira AM, Dekkers OM, van Furth WR, Biermasz NR. Improvement in symptoms and health-related quality of life in acromegaly patients: a systematic review and meta-analysis. J Clin Endocrinol Metab 2021; 106: 577-87. 